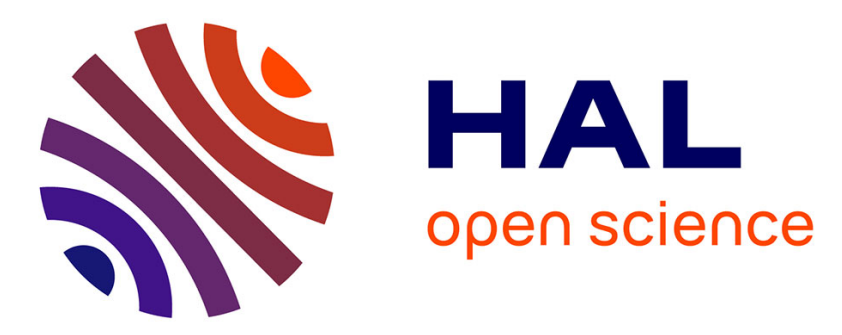

\title{
Response article Full transfer vs. developmentally moderated transfer: a reply to Bohnacker \\ Manfred Pienemann, Gisela Håkansson
}

\section{To cite this version:}

Manfred Pienemann, Gisela Håkansson. Response article Full transfer vs. developmentally moderated transfer: a reply to Bohnacker. Second Language Research, 2007, 23 (4), pp.485-493. 10.1177/0267658307080332 . hal-00570735

\section{HAL Id: hal-00570735 \\ https://hal.science/hal-00570735}

Submitted on 1 Mar 2011

HAL is a multi-disciplinary open access archive for the deposit and dissemination of scientific research documents, whether they are published or not. The documents may come from teaching and research institutions in France or abroad, or from public or private research centers.
L'archive ouverte pluridisciplinaire HAL, est destinée au dépôt et à la diffusion de documents scientifiques de niveau recherche, publiés ou non, émanant des établissements d'enseignement et de recherche français ou étrangers, des laboratoires publics ou privés. 


\section{Response article Full transfer vs. developmentally moderated transfer: a reply to Bohnacker}

Manfred Pienemann Paderborn University and Newcastle University and

Gisela Håkansson Lund University

Received March 2007; revised April 2007; accepted April 2007

Ute Bohnacker's (2006) article on the acquisition of the verb second (V2) property in German by native speakers of Swedish (also a V2 language) is an attempted rebuttal of Håkansson et al.'s (2002) work on first language (L1) transfer and aspects of the underlying theory on which the work is based: Processability Theory (Pienemann, 1998). The article by Håkansson et al. presented empirical evidence from a similar population of learners (native language Swedish, target language German), showing that V2 is not transferred at the initial state. Unfortunately, Bohnacker misrepresents key aspects of our work on L1 transfer and, paradoxically, her own data constitute empirical evidence supporting our position, as we show in this response.

Keywords: transfer in L2, Processability Theory, L2 vs. L3 German, verb second, initial state

\section{Some misunderstandings about Håkansson et al. (2002)}

It may be useful first to consider the key theoretical positions that Bohnacker presents as offering opposing sets of assumptions.

Address for correspondence: Manfred Pienemann, Department of English and American Studies, Universität Paderborn, Warburger Straße 100, D-33098 Paderborn, Germany; email: pienemann@ zitmail.upb.de 
1) A 'no-transfer' position that is incorrectly attributed to us. Bohnacker assumes that the following are entailed by this position:

- There is a universal canonical SVO (subject-verb-object) word order at the initial state (pp. 443, 445-46).

- The syntactic property of V2 never transfers (pp. 443, 446).

- The extent of transfer is unpredictable if second language (L2) properties are allowed to transfer to the third language (L3) (p. 479).

2) The full transfer / full access position of Schwartz and Sprouse (1996).

We need to point out that none of the assumptions listed under (1) is shared by us: neither in our current work nor in those of our publications quoted by Bohnacker. Instead, our position, which is articulated from a typological and a psycholinguistic perspective by Pienemann et al. (2005), is one of partial transfer. It is called the Developmentally Moderated Transfer Hypothesis (DMTH), and it is based on Processability Theory (PT) (Pienemann, 1998) and its extension (Pienemann et al., 2005), which also includes assumptions about the initial state, some of which are inferred from Lexical Mapping Theory, a component of Lexical-Functional Grammar (Bresnan, 2001). According to the DMTH and PT, different types of word order may be present at the initial state in different languages. Pienemann et al. (2005) have demonstrated this empirically in longitudinal studies of the L2 acquisition of several non-SVO languages (including Japanese).

Contrary to Bohnacker's reading, the DMTH does not assume that '[t]he syntactic property of V2 never transfers' (p. 443). Instead, it assumes that V2 is not transferred at the initial state, and it may be transferred when the interlanguage (IL) system can process it. PT makes exact predictions about the processability of specific structures. Hence, this hypothesis is readily testable. As we will show below, it is exactly this developmentally moderated effect that Bohnacker's own data show so clearly. Further evidence supporting the DMTH is presented in Pienemann et al. (2005).

In relation to $\mathrm{L} 2$ transfer, Bohnacker attributes the following position to us: 'if we allowed for L2 syntax to transfer to the L3, the extent of transfer would be unpredictable, unless L2 transfer were to be total, leaving no room for L1 transfer.' She adds: 'I do not see why this should be so. 
For domains other than syntax, there is ample documentation of L2 transfer alongside L1 transfer' (Bohnacker, 2006: 479). This does not reflect our position correctly. Instead, we argued that a theory of L2-to-L3 transfer would need to include a testable component that can predict when features of the L2 will be transferred to the L3, when properties of the L1 will be transferred and where this transfer alters the route of acquisition. We added that no such theory exists. This lack of operationalization and testability has been a problem for many early theories of L1 transfer, which merely attained the status of post hoc explanations. We argued that in the absence of a testable theory of partial L2 transfer (at the initial state) one could only test a version of full L2 transfer or full L1 transfer, and that this is at odds with our Swedish-German data. Bohnacker assumes that the lack of V2 transfer from Swedish to German in our data is due to the transfer of SVO from L2 English. We argue that if this were correct then why were other features of English not transferred, such as 'adverb-first' or 'particle' (the position of non-finite parts of the verbal complex such as particles, participles and infinitives in relation to the finite verb)? Hence, Bohnacker's assumption of SVO transfer from English amounts to a very specific assumption about selective transfer for which she offers no theoretical support. A consistent transfer-based explanation of our data would need to spell out exactly which of the two languages, L1 or L2, the learner will transfer from in which precise circumstances. Everything else is purely speculative, whereas the developmental account of our data is internally fully consistent.

\section{Reanalysing Bohnacker's evidence}

Let us now turn to the empirical evidence produced by Bohnacker. Bohnacker claims that Swedes learning German as the first L2 start with V2. This is the key point she needs to demonstrate in the analysis of her corpus. Given that she contrasts this claim with our claim that Swedes learning German as L2 start with canonical word order, her analysis ought to have used the same methods of data analysis and acquisition criteria (i.e. implicational scaling and the emergence criterion). Instead, her analysis focuses on mere quantitative differences between learners. She shows that the first-time learners have a higher rate of accuracy in V2 positions after sentence-initial non-subjects. However, this is not at all the same as 
showing that the first-time learners start with V2 because accuracy is not a reliable measure of development (see Pienemann, 1998). It has been demonstrated many times that a high rate of accuracy on a structure does not imply that it was acquired early (see also Meisel et al., 1981). In order to demonstrate that Swedes learning German as the first L2 start with V2, Bohnacker would have needed to show that V2 appears in the first L2 sentences with initial non-subjects produced by her L2 learners without previous knowledge of English, and in order to demonstrate that the other group $($ German = L3, English = L2) starts with SVO as the initial hypothesis, she would have needed to show that the first sentences produced by these learners are exclusively SVO.

In order to subject Bohnacker's data to a valid test of the learner's current level of acquisition, we re-analysed it in the form of an implicational scale using the emergence criterion. This was done on the basis of the quantitative data presented in Tables 2-5 and Tables 8-9 (Bohnacker, 2006). Our re-analysis is presented in Table 1 , which is laid out as follows. The first column shows whether German is the L2 or the L3 of the informant. The second column identifies the sample by informant name and 'data point' number. The column entitled 'SVX' indicates whether the sample contains examples of canonical word order (using the emergence criterion) where '+' means 'acquired'. The column 'ADV' does the

Table 1 Re-analysis of Bohnacker's sample using the same criteria as in Håkansson et al., 2002

\begin{tabular}{llllll}
\hline L2 or L3? & Informant & SVX & ADV & SEP (\%) & V2 (\%) \\
\hline L2 German & Märta 1 & + & + & $12^{*}$ & 100 \\
L2 German & Märta 2 & + & + & $12^{*}$ \\
L2 German & Märta 3 & + & + & 70 & 100 \\
L2 German & Algot 1 & + & + & 30 & 100 \\
L2 German & Algot 2 & --- & --- & -- & 100 \\
L2 German & Algot 3 & + & + & 85 & --- \\
L2 German & Signe 3 & + & + & 62 & 100 \\
& & & & & \\
L3 German & Rune 1 & + & + & $8^{*}$ \\
L3 German & Rune 2 & + & + & $8^{*}$ & 55 \\
L3 German & Rune 3 & + & + & 76 & 44 \\
L3 German & Gun 1 & + & + & 45 & 58 \\
L3 German & Gun 2 & --- & -- & -- & 55 \\
L3 German & Gun 3 & + & + & 70 & 57 \\
L3 German & Ulf 3 & + & + & 61 & 52 \\
\hline
\end{tabular}

Note: * The figures for Märta $1+2$ and Rune $1+2$ are presented as averages of the two sessions by Bohnacker 
same for structures with non-subjects in initial position. The column 'SEP' (verb separation) lists the relative frequency of two verbs (aux $+\mathrm{V}$ ) appearing in a non-adjacent position (i.e. XVYV). The last column lists the relative frequency of V2 application. In other words, the columns from SVX to V2 are arranged in the order of acquisition that has been found in many previous second language acquisition studies and that was initially identified by Meisel et al. (1981).

It is easy to see that all four target structures meet the emergence criterion for all informants. No cell of the implicational table is empty (apart from missing data for Algot 2 and Gun 2), no learner slides back and, thus, the scalability of Table 1 is $100 \%$. This means that all structures under discussion, including V2, had already been acquired at the first point of data collection. In other words, all informants had acquired V2 (and all the other relevant structures) at the beginning of the study. This is the strongest reason why the study is not suitable to test the initial word order of Swedish first-time learners of German. Given that the learners had already acquired all the structures under investigation at the beginning of the study, including V2, they are simply too advanced to make any statement about the initial state of their interlanguages.

One might object to our conclusion about the level of acquisition of the six learners in Bohnacker's corpus on logical grounds, because full transfer from Swedish would always imply that all structures contained in Table 1 need to be present from the start. One might argue that this follows logically from the fact that these structures are all part of Swedish and German. However, such a conclusion is not warranted for a number of reasons.

First of all, the full transfer assumption would require a contradictory treatment of the two subgroups of learners in the analysis presented in Table 1. Bohnacker's corpus consists of two subsets: L2 learners of German and L3 learners of German with English as L2. In line with the above hypothetical objection to our analysis of Bohnacker's data, the full transfer assumption would imply that the first group (with German as the only L2) is at the initial state in the first data collection session. Bohnacker claims that at the initial state L3 learners of German transfer their grammatical knowledge from their L2 (English) to their L3 (German). This means that these learners will transfer SVO and ADV at the initial stage, 
but not the rules SEP and V2, because these are not part of English. However, Table 1 shows that the learners marked 'L3 German' have acquired more rules than only SVO and ADV. Instead, they have also acquired SEP and V2 in the first data collection session. Therefore these learners cannot be at the initial state of L3 acquisition under a full transfer assumption. The only logical conclusion the advocate of the full transfer hypothesis could draw from this observation is that the L3 learners have progressed to level 5 of the PT hierarchy (V2) in the first data collection session. This would imply that the presence of all four grammatical rules in the interlanguage samples in the first data collection session would be interpreted as evidence for the initial state for the L2 learners and as evidence for stage 5 for the L3 learners.

In contrast, our analysis does not require such a contradictory analysis. We draw one and the same conclusion from the same observational facts for all learners, namely that from the first data collection session onwards (i.e. after four months of German classes) all learners are at level 5 of the PT hierarchy. This is also consistent with the learners' high level of motivation to learn German: As Bohnacker points out, they learn this language to communicate with the other set of grandparents who are monolingual and German-speaking (i.e. their grandchildren grow up bilingually because their son-in-law or daughter-in-law is from Germany or Austria).

Second, the non-adjacent position of aux and $\mathrm{V}$ is a very rare optional feature of Swedish main clauses that is limited to a small number of syntactic contexts. In fact, it is so infrequent that it never appeared in a large Swedish corpus (see Platzack, 2003). In contrast, this structure is obligatory in German, and it applies to all contexts in main clauses with aux/ mod and V. Nevertheless, this feature was produced by all learners who took part in the first data collection session:

$\begin{array}{lrl}\text { Märta 1 } & 12 \% & \text { (L2 German) } \\ \text { Algot 1 } & 30 \% & \text { (L2 German) } \\ \text { Rune 1 } & 8 \% & \text { (L3 German) } \\ \text { Gun 1 } & 45 \% & \text { (L3 German) }\end{array}$

In the case of first-time learners of German one would need to explain the mechanism that allowed them to generalize a highly constrained L1 rule to far less constrained L2 contexts. In the case of the L3 learners of German the situation is even more contradictory, since these learners should not produce SEP at all because the non-adjacent position of aux 
and $\mathrm{V}$ does not occur in English (except in very rare cases in written corpora). In this situation Bohnacker might appeal to transfer from the L1. However, this would mean that recourse to either L1 transfer or L2 transfer would be unprincipled and post hoc. Such an approach is unfalsifiable. Using only the full transfer assumption, in turn, leads to false predictions as we showed above.

Bohnacker implies that the higher accuracy rate in $\mathrm{V} 2$ in her data shows that V2 is acquired earlier than SEP. In other words, she uses the same equation as above: 'high accuracy equals early acquisition'. We pointed out that this assumption has been demonstrated to be false. Furthermore, by reanalysing her data using implicational scaling and the emergence criterion, we have shown that both structures are present in her corpus in a very consistent manner and not that one is acquired before the other.

\section{Accounting for differences between the $\mathrm{L} 2$ and $\mathrm{L} 3$ groups}

There is one striking difference between the L2 and the L3 group data presented in Table 1. The learners without exposure to English display a native level of performance for V2 (i.e. 100\% in nearly all samples), whereas learners with exposure to English do not. In other words, the L2 learners are not only more accurate with V2 than the L3 learners, but their use of V2 is categorical: like that of native speakers. Clahsen and Muysken (1989) found a similar differential pattern in the acquisition of German V2 by L1 and L2 learners, where L1 learners displayed an almost instant increase to native behaviour and L2 learners displayed a slower learning process with persistent non-native rule application. Here too, one group displayed categorical learning.

This is highly compatible with our developmentally moderated transfer hypothesis, which predicts that transfer will not appear before the structure to be transferred can be processed by the IL system. However, when structures from the L1 or L2 are processable, they may be transferred to the target language, and this may lead to differential patterns of language use in groups of learners with different L1s (or L2s). We ascertained above that all informants in Bohnacker's corpus have reached the acquisition level where V2 is processable. The group without knowledge of English has recourse only to their knowledge of V2 that is transferred at this point of development, whereas the group with English as the first L2 transfers 
two competing rules that match the structural condition for V2, i.e. either XVSY or XSVY. Therefore the given learning condition facilitates the accuracy with which the L2 group uses V2 compared with the L3 group.

\section{Conclusions}

As the re-analysis of Bohnacker's data has shown, the crucial difference between her favoured full transfer position and the developmentally moderated transfer hypothesis is that of the timing of transfer. The full transfer position assumes that transfer occurs at the initial state, whereas we assume that it occurs when the structure to be transferred can be processed. Pienemann et al. (2005) reviewed research on transfer from a processing and a typological perspective and included a number of extensive second language acquisition studies demonstrating that L1 transfer at the initial state is in no way guaranteed. For instance, Di Biase and Kawaguchi (2002) showed in a longitudinal study that Australian learners of Japanese produce SOV (subject-object-verb) from the time they produce the first sentences rather than transferring English SVO as would be predicted from a full transfer position. In a similar vein, Di Biase and Kawaguchi (2002) showed that Australian learners of Italian used pro-drop in their first sentences rather than transferring non-pro-drop from English. These studies substantially weaken the full transfer position. In both studies the typological gap between L1 and L2 was able to be bridged despite marked structural differences - as shown by Pienemann et al. (2005) - because the L2 structures are readily processable at an early level of acquisition.

\section{Acknowledgements}

We would like to thank the following people for helpful comments on this article: Bruno Di Biase, Felix Hoffmann, Satomi Kawaguchi, Dagmar Keatinge, Jörg Keßler, Anke Lenzing, Ingo Plag and Yanyin Zhang.

\section{References}

Bohnacker, U. 2006: When Swedes begin to learn German: from V2 to V2. Second Language Research 22, 443-86.

Bresnan, J. 2001: Lexical-functional syntax. Oxford. Blackwell

Clahsen, H. and Muysken, P. 1989: The UG paradox in L2 acquisition. Second Language Research 2, 1-29. 
Di Biase, B. and Kawaguchi, S. 2002: Exploring the typological plausibility of Processability Theory: language development in Italian second language and Japanese second language. Second Language Research 18, 274-302.

Håkansson, G., Pienemann, M. and Sayehli, S. 2002: Transfer and typological proximity in the context of L2 processing. Second Language Research 18, $250-73$.

Meisel, J, Clahsen, H. and Pienemann, M. 1981: On determining developmental stages in natural second language acquisition. Studies in Second Language Acquisition 3, 109-35.

Pienemann, M. 1998: Language processing and second language development: Processability Theory. Amsterdam: Benjamins.

Pienemann, M., Di Biase, B., Kawaguchi, S. and Håkansson, G. 2005: Processability, typological constraints and L1 transfer. In Pienemann, M., editor, Cross-linguistic aspects of Processability Theory. Amsterdam: Benjamins, 86-116.

Platzack, C. 2003: The verb phrase. In Josefsson, G., Platzack, C. and Håkansson, G., editors, The acquisition of Swedish grammar. Amsterdam: Benjamins, 135-54.

Schwartz, B.D. and Sprouse, R.A. 1996: L2 cognitive states and the Full Transfer/Full Access model. Second Language Research 12, 40-72. 